\title{
In Memoriam Hymie L. Nossel
}

Hymie L $\cdot$. Nossel was born in 1930, studied at the University of Cape Town, and obtained his D. Phil, at the University of Oxford in 1962. He was made a Fellow of the College of Physicians of South Africa in 1958, and of the Royal College of Physicians, London in 1980.

At the time of his death, he was Professor of Medicine, College of Physicians and Surgeons, Columbia University, and Attending Physician at Presbyterian Hospital, New York City; a member of 11 scientific societies; Chairman elect of the Council, International Society on Thrombosis and Haemo-stasis; and editor of the following journals: Journal of Biomedical Materials Research, Haemostasis, and Blood.

A list of 69 articles and 26 reviews, chapters and books shows the width of his expertise. Surface activation of factor XII and of factor XI, inhibition of factor XI, properties of collagen affecting clotting versus platelet adhesion, and elaborate and essential studies of fibrinopeptides $\mathrm{A}$ and $\mathrm{B}$ are among the

subjects of his articles. He contributed and later updated his important chapter, 'The Contact System', in Human Blood Coagulation, Haemostasis and Thrombosis (R. Biggs, ed.), but also co-authored the book Patho-biology of the Endothelial Cell.

From his curriculum vitae, it is obvious that he made very significant contributions both to basic knowledge of events leading to and following thrombosis, and to future patient care, but the gentle, modest and reliable person that Hymie was, barely peeks out between the lines. Above all, perhaps, he was considerate, in the careful ways he handled his data as well as in the thoughtful way he approached people. He died on October 9, 1983 of a massive heart attack. Relying on his always reassuring, stabilizing presence, as all who knew him did, we were shocked by his sudden absence. He leaves us his wife, his three children and his very many friends.

He continues to prove to us that matters of the heart survive the heart itself.

Leo Vroman 